\title{
From Classroom to Online Teaching: Experiences in Improving Statistics Education
}

\author{
ANNE PORTER $\dagger$ \\ alp@uow.edu.au \\ School of Mathematics and Applied Statistics, University of Wollongong Australia \\ DAVID GRIFFITHS \\ david_griffiths@uow.edu.au \\ School of Mathematics and Applied Statistics, University of Wollongong Australia \\ JOHN HEDBERG \\ john_hedberg@uow.edu.au \\ Faculty of Education, University of Wollongong Australia
}

\begin{abstract}
This study used reflective practitioner methodology to investigate how to improve the quality of statistical education. During the study, this methodology, curricula, pedagogical practices, assessment and a framework for learning to learn statistics were all developed as means of improving the quality of statistical education. Also documented was the move from being a classroom teacher of statistics to a teacher who is developing learning resources for online delivery to students. For a classroom teacher, flexible delivery has meant drawing on the sights, sounds, movement, quiet and live shows. By contrast, the online teacher feels the constraints of translating activity based programs to technologically based programs. As more students have chosen to rely on online materials rather than classroom activities, the focus of improving quality has been extended to the enrichment of online resources, so that the learning experience is not second to that of the classroom.
\end{abstract}

Keywords: activity based learning, learning online, reflective practice, teaching statistics

\section{Introduction}

Given the dynamic nature of the classroom environment and the complexity of learning, it is little wonder that researchers have begun to ask as to the nature of appropriate methodology to study statistical education. As Jolliffe [6] suggested, controlled experiments are difficult, and it is not always practical or ethical to conduct such studies. Papers written by statistical education researchers often focus on singular changes introduced to the learning environment. For example, the majority of changes reported

$\dagger$ Requests for reprints should be sent to Anne Porter, School of Mathematics and Applied Statistics, University of Wollongong Australia. 
in the papers presented at The Fifth International Conference on Teaching Statistics, held in Singapore in 1998, were singular changes. Most changes could be classified as the introduction of activities to demonstrate principles, the use of real world data, introduction of software, technology and multimedia to the classroom, selection of appropriate textbooks and teaching with a theme. The outcomes suggested are also diverse; they include changes in motivation, engagement, removal of fear and anxiety, greater understanding, interest, learning and retention, pace of learning and achievement. Research can address the macro level changes over an entire subject, or examine changes in learning at a micro-level. See, for example, the work on the meaning of specific concepts [4]. The evidence provided is often by way of researcher commentary. As Chance and Garfield [5] indicate, there is little by way of documentary evidence in statistical education research as to whether changes enhance student learning, retention and appreciation of statistics.

There are many research methodologies available to study improving the quality of teaching and learning. Furthermore, there are frameworks available for the evaluation of educational innovation (see for example [3], [1]). This paper draws on the methodology of reflective practice incorporating both reflection-in-practice and reflection-on-practice [11]. Reflective practice as used in improving the statistical education of students in this paper was further defined [10] as an ongoing methodology, a means of systematically gathering and exploring evidence from students, including comparing teachers' thoughts on issues with evidence and ideas expressed in the literature.

The discussion in this paper is based on a study of students initiated at the University of Wollongong in 1993. That study of how to improve statistical education continues today. The initial statistical literacy subject providing data for this research was offered to students in a tertiary access program. The classes were small (maximum 30 students), the students were from educationally disadvantaged backgrounds, and the subject, or variations of it, was taught many times from 1993 - 1997. This study extended to another context, the teaching of large introductory statistics classes (with class size 100-300 students), once again with teaching repeated over several years beginning in 1997.

The findings from the small classroom suggested that, to improve the teaching and learning of statistics, one needs to reflect upon and often to modify the curriculum, teaching practices, the learning framework, assessment practices, and the reflective practices used.

The move to large lectures necessitated the development of systems to manage resources and personnel. To facilitate activity based teaching and 
learning, a manual of exercises and other online learning resources were developed and made available to support students' learning. In this instance, resources have been provided using WebCT as the software delivery vehicle. This innovation has led to more flexible options for students, one being the prospect of learning solely online rather than going to lectures, although these and other learning resources are presented as being complementary. However, the provision of online resources has substantially changed the learning environment. Many students feel, perhaps erroneously, that they no longer need to participate in the classroom. This change has necessitated development of enriched online facilities.

\section{Determining Curriculum}

A first step to improving statistical education is to ask what should be included in statistics curricula. Phrased simply 'what are the fundamental statistical concepts or ideas?'. This question becomes a little more complicated when we ask how these ideas link together, and still more complex when different discipline contexts are added. To address these questions in this study, several techniques were used to unpack statistical experts' expertise and to unpack the teacher's own expertise as a statistician (see $[2]$ ). The primary methods involved concept mapping [9] of textbooks and academic literature to identify key concepts and the manner in which those concepts are linked.

As a consequence of the process of unpacking statistical expertise of self and other statisticians, the curriculum theme adopted was statistics is a study of variation throughout the research or problem solving process. As such, it is possible to examine questions/hypotheses, measurement, experimental design, analysis and the drawing of conclusions about data from the perspective of how each phase in the research process relates to variation. In so doing, one uses a language that is inclusive of the term variation for example, one speaks of variation over time rather than time series, variation due to measurement rather than measurement error and so on.

\section{Teaching Practices}

To improve quality, one must also examine teaching strategies. One needs to recognize that teaching takes place in the context of students' lives and that students

...have a life both within and outside the current learning episode and, whilst learning, they may be endeavoring to compose a future 
life. The teacher needs to establish pedagogical practices that engage the students in the learning process. Engagement may serve a variety of functions and be accomplished in different ways for different students. ([10] p. 343.)

To engage students in the statistical literacy subject, teaching was activity based rather than delivered through a traditional lecturing mode. Segments within teaching in both lectures and small classes followed a basic pattern, in Kelly's ([7] and [8]) terms, of loosening students thinking with an activity and then tightening thinking with a debriefing. The sequences of teaching may be: activity - think and discuss - teacher debrief; tell a story - questions and discussion - formalize and extend theory; review - integrate material - make explicit the ideas. The aim of the activities was to surprise students with their own knowledge (it was never about telling them the obvious). To teach in this manner, the teacher needed to be able to anticipate the outcomes and to be able to handle the unexpected. The stories used to weave students' ideas together into a lecture needed to be flexible but the development of the plot or theory was not.

Activity itself was found to be insufficient for the engagement of students. For the students to engage in learning, the following were critical.

- The teaching activities needed to be directed at establishing authenticity and meaning, illustrating the relevance of statistics to student lives, student thinking and decision making and to the future disciplines within which the student may work.

- The teaching approach positioned both the teacher and students as learners, drawing upon ideas that came from students' activity and discussion. As the activities were enacted, the teacher identified gaps in student logic and deficiencies in the teaching segments. The teacher learned about the impact of various pedagogical practices on students and teacher. Students understood that knowledge was not immutable and predefined, but that they were also the creators of knowledge. They could think the ideas before they were given instruction.

- The engagement had to lead to ideas embedded in the curriculum, namely that statistics is a study of variability. This was essential for students to understand statistics.

An example of an activity based exercise used to establish that statistics is a study of variation follows.

Problem A local community group has called for a statement regarding possible damage caused by a maritime accident. 
Task Your task is to come up with a list of questions that you would want answered and what you would want to see or know before you accept a report that says there was or was not damage to the sealife caused by the accident.

Data The only data are two sets of shells (a measure of sealife), one collected before the accident and the other after.

The questions which can generally be elicited by students when given this task may be classified as pertaining to: ethical issues (were the report writers biased?); clarification of the question (is it variation in the sea life which have shells or all sea life that is to be examined?); design issues (were the data collected during the same season, with the same water temperatures, with the same tides?); sampling issues (were the shells sampled from the same places on the beach?); how to measure differences (is it a change in the number of species, the number of shells or the size of the shells that is to be examined?); how to represent data; how to draw conclusions about causality; and finally how to determine if there is a real variation caused by the accident when the number of shells changes every day. Whatever the answers to each of the above questions, a broader question should be posed: does the narrow focus of the study design allow us to properly address the impact of the maritime accident?

Activities as a basis for teaching can be used successfully with both large classes and with technical material. The difficulty is finding suitable activities.

\section{Learning Framework}

There are many learning issues that students confront when studying statistics. In this study, the teacher of these subjects developed an explicit focus (an implicit one was insufficient) on how to learn. In recent years, the first lecture activity involves students in dancing. It is unexpected, they are surprised and they think what on earth is this lecturer doing, they do it (master the how) and wonder why they are doing it and if they are likely to have to do it again (when). The teacher tightens, making specific reference to learning issues and the need to focus on what, how, why and when in understanding any statistical technique. The why is explicitly stated as 'Statistics is about variation in the world around us. Everything learned will in some way relate to variation'. Issues arose such as the need to participate when learning and the need to tolerate feeling uncertain. Throughout the subjects, the learning to learn focus was again discussed, as the teacher became aware of students encountering learning issues. 
The nature of the learning issues is likely to vary from teacher to teacher and class to class. Students often feel they can do the statistics, but not necessarily understand ideas and this creates an uncomfortable feeling for them. Even when students can generate appropriate statistical ideas they can feel at a loss, thinking they do not understand because they do not know the language of mathematics and statistics. Activity of itself does not necessarily generate learning; it needs tightening principally through assessment involving both writing, problem solving or even concept mapping. When students are asked to write (tighten their ideas) they often confuse the lack of writing skill with lack of understanding statistics. Ironically one of the greatest difficulties these students confront, and particularly associated with activity based teaching, is the feeling of uncertainty, 'what specifically do I need to know' and yet statistical solutions by their nature are probabilistic, not deterministic. A second irony that appeared when teaching in this manner was that some students could only focus on the outcome of their particular activity, while others could look only at the overall class outcomes. Statisticians identify general patterns in data but at the same time need to look at the unusual and perhaps individual pieces of data.

\section{Assessment}

Teaching through activities is of itself insufficient to bring about learning. A necessary component is that students themselves reflect upon the activities undertaken in class. The assessment system is a powerful learning tool and is also useful for examining the nature of students' thinking. Assessment is the point at which many students come to doubt their understanding and writing ability, and to experience anxiety and uncertainty as they attempt to tighten their own ideas.

For the initial small groups of 25-30 students studied, assessment involved 4-5 short papers on individual activities; a major project where they were to reflect on all the statistical ideas they had encountered and an exam involving interpretation, simple calculation, and concept mapping. The short papers revealed how students thought and highlighted students' writing difficulties. For the short papers students were basically asked to reflect on the activity and explain those ideas in a new context. Students would often focus on the hard ideas, not on good coverage of ideas. Students often felt they had not learned if they had not experienced difficulty. Students needed to learn that the lecturer's commenting on their assignments was desirable, and not a punishment. Extensive comment was provided, whatever the standard of work. Marking became process rather than content 
orientated as the teacher discovered that students needed to learn when to make statistical decisions, before they necessarily made correct interpretations or decisions.

In large classes, two open-ended projects were set. To ease the marking, they were completed by students in pairs and marked with a software assistant, Mindtrails. Students however needed to be instructed that the team was not meant to be a division of labor but rather was to provide a buddy, a sounding board, someone else to discuss ideas with.

\section{On-line Resources}

To free students from writing and hence to free them to participate in activities in lectures has involved the development of online resources through WebCT. Students have been provided with lecture notes, worked solutions to exercises, remediation modules and a means of communication with the lecturer and other students. While successful as support mechanisms, these materials have also meant that in the most recent delivery of the subject, approximately one-quarter of students have chosen to cover the lecture material solely online.

A difficulty emerged when online resources became sufficiently comprehensive that students were choosing to rely solely on these. Materials used to replace a lecture need to be richer than materials used to support a lecture. The use of activity based lectures was to engage students, and in particular to engage them with the concept that statistics is a study of variation. Reading about variation is not the same as experiencing the different guises of variation.

To create a more dynamic online learning environment, two possibilities are currently being explored: the inclusion of applets (or simulations) and video materials. Video materials are used to provide classroom context and to provide real world context. Excellent commercial video is available, for example, the Decisions Through Data Video series. (These are shortened versions of the Against All Odds series.) However it is relatively simple to create short clips (2-3 minutes), to illustrate events which may follow various models. Examples developed for this course include counting processes (Binomial: number of females in a litter of pet mice; Poisson: eruption of a blowhole, traffic in two directions). The option of creating one's own video and/or sharing free video with other statistical educators becomes important outside the classroom because of copyright issues for web based or CD ROM materials. 


\section{Conclusion}

The classroom is too dynamic to describe all that is deliberate in teaching. Teaching involves timing, peer teaching, forms of assessment, writing, interactive teaching style, stories told, quiet and noisy times. It also involves integrating from one lecture to the next, integration within lectures, review, introduction of new ideas, identifying students logical order of thought. In this study, reflective practice was deemed to be the key to improvement in the quality of teaching and learning. Improvements to the curriculum and the sequencing of ideas were associated with improvements in achievement while the creation of an explicit learning framework was the key to improving student attitudes towards learning statistics.

Online learning has assumed an important role, providing students with alternative pathways to study. However, in a situation where students have choice, after six years of development, 33 percent of students choose to attend lectures only, 25 percent online only, 40 percent use lectures and online, and 2 percent other means. A continuing challenge for statistics (and other) educators is to persuade students of the richer learning opportunities available through accessing all available delivery modes, and to obtain evidence as to whether the perceived negative effect of choosing the 'online only' mode is real even when the online resources are 'adequate'.

Reflective practice is more than thinking about what one is doing as a teacher. Reflection may involve the collection of data by asking students to respond in writing in a couple of minutes to questions asking 'how does it feel?' or 'what sense does that make?' Having open ended assessment tasks and writing responses is revealing to both student and teacher. Reflection involves the upending of assumptions about how students learn. As educators we need to turn thinking from 'it is the student's fault' to 'it is my failure to connect, motivate, engage, simplify, make real, provide alternatives that is problematic'. We need to examine what we do through different learning theory perspectives. We need to examine the meaning of the terms we use so as to ascertain why one technique works for one teacher but not another. We need to detect the nuances in meaning. For a reflective practitioner the task is never complete, but where reflective practice involves close listening to students and identifying what it is they understand and feel, it is a powerful technique for improving statistical education. 


\section{References}

1. S. Alexander and J. Hedberg. Evaluating technology-based learning: Which model? In K. Beattie, C. McNaught, \& S. Wills (Eds.), Multimedia in higher education: Designing for change in teaching and learning. Elsevier, Amsterdam, pp. 233-244, 1994.

2. J.D. Bain. Unpacking the expert to teach the novice. Proceedings of the 8th Australasian Tertiary Learning Skills and Language Conference, Queensland University of Technology, Brisbane, pp. 119-127, 1990.

3. J.D. Bain. Editorial. Higher Education Research and Development, 18(2):165-172, 1999.

4. M.C. Batanero, and J.D. Godino. Developing new theoretical tools in statistics education research. Education Bulletin of the International Statistical Institute, 53rd Session Proceedings, Book 2. International Statistics Institute, Seoul, pp. 197200, 2001.

5. B.L. Chance, and J.B. Garfield. New Approaches to gathering Data on Student Learning for Research in Statistics. Education Bulletin of the International Statistical Institute, 53rd Session Proceedings, Book 2. International Statistics Institute, Seoul, pp. 205-208, 2001.

6. F. Jolliffe. What is research in statistical education? In L. Pereira-Mendoza, L. Sue Kea, T. Wee Knee, \& W.K. Wong (Eds.), Proceedings of the Fifth International Conference on Teaching Statistics. International Statistics Institute, Singapore, pp. 801-806, 1998.

7. G.A. Kelly. The Psychology of Personal Constructs: A theory of personality. (Vol 1). Norton, New York, 1955a.

8. G.A. Kelly. The Psychology of Personal Constructs: Clinical Diagnosis and Psychotherapy. (Vol. 2). Routledge, New York, 1955 b.

9. J.D. Novak and D.B. Gowin. Learning how to learn. Cambridge University Press, Cambridge, 1984.

10. A.L. Porter. Improving Statistical Education Through The Experience Of Reflective Practice. Doctoral thesis, University of Wollongong, NSW, Australia, 2001.

11. D.A. Schön. The Reflective Practitioner: How Professionals Think in Action. Basic Books, New York, 1983. 


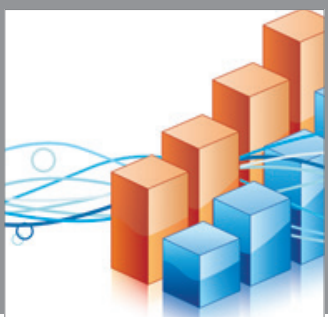

Advances in

Operations Research

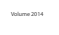

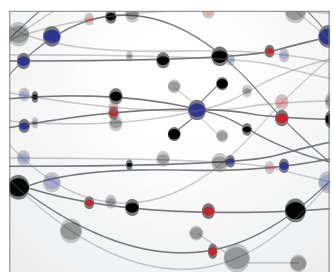

\section{The Scientific} World Journal
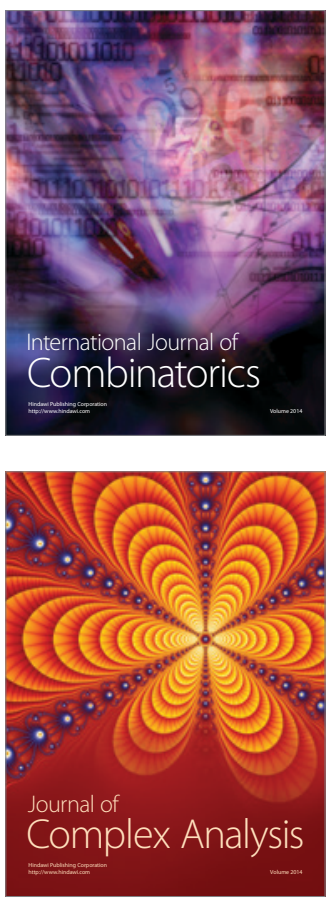

International Journal of

Mathematics and

Mathematical

Sciences
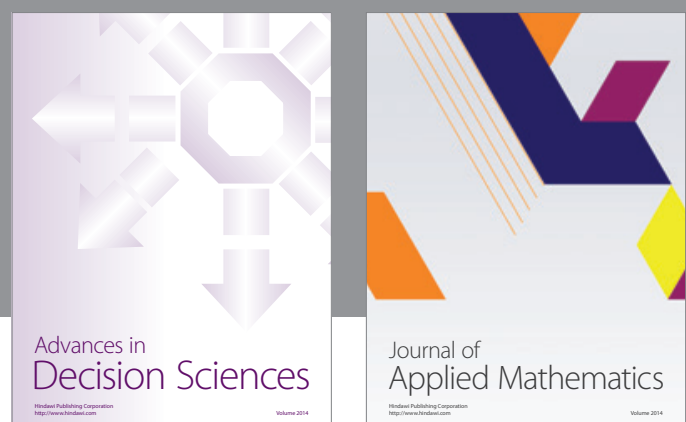

Journal of

Applied Mathematics
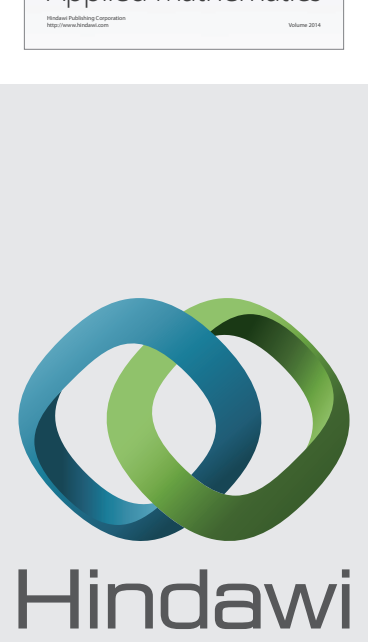

Submit your manuscripts at http://www.hindawi.com
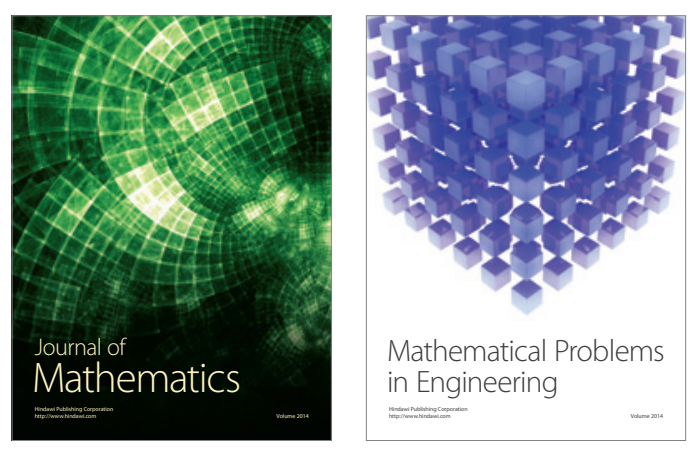

Mathematical Problems in Engineering
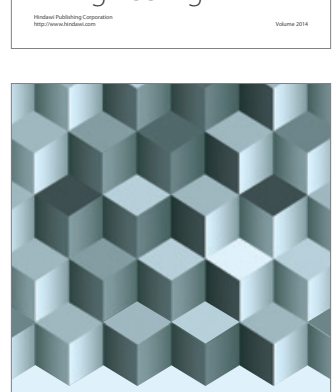

Journal of

Function Spaces
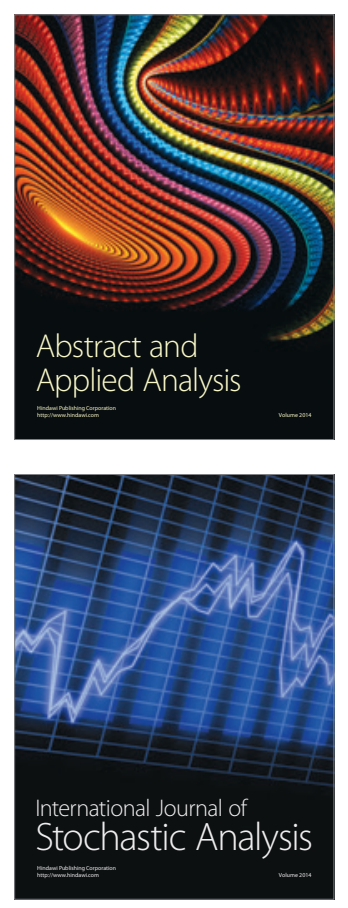

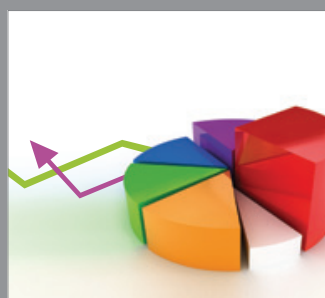

ournal of

Probability and Statistics

Promensencen
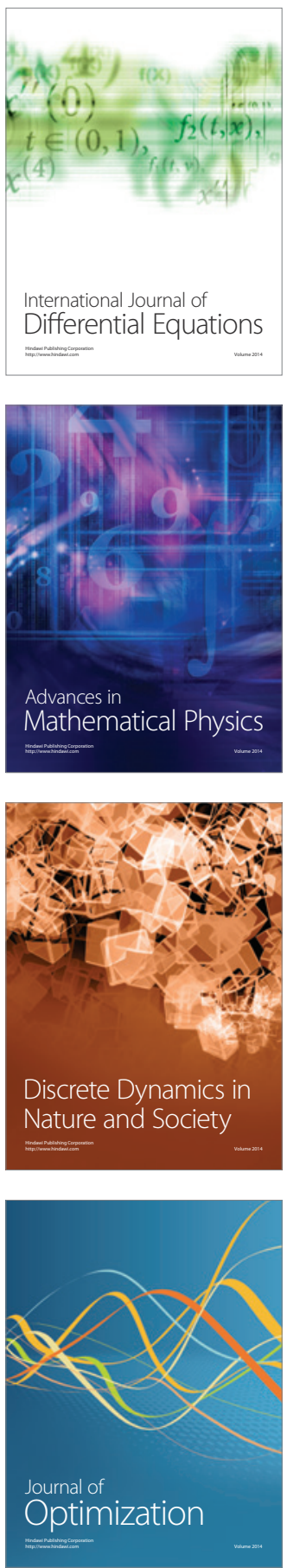